\title{
Acuerdo Andaluz por el Agua
}

Documento suscrito por la Junta de Andalucía y los principales Agentes Sociales andaluces el 3 de febrero de 2009.

\section{INTRODUCCIÓN}

El agua es un patrimonio común fundamental para la vida, el bienestar económico y la vertebración del territorio, pero es un recurso finito y vulnerable al que hay que cuidar para poder garantizar el abastecimiento de la población, la prosperidad económica y las necesidades medioambientales.

Es necesaria una nueva ética del agua que tenga en cuenta la fragilidad del recurso y sepa hacer compatible la garantía de las demandas de todos los usos con el cuidado del medio ambiente, pues la calidad de vida de los andaluces, la ordenación de las actividades económicas y del territorio y el desarrollo de políticas sociales adecuadas dependen en gran parte de la buena gestión del agua.

Todos lo usuarios debemos ser conscientes de que tenemos una responsabilidad colectiva con el agua: conservarla en cantidad y calidad, usarla con sensatez y ser solidarios con aquellos que tienen más difícil el acceso a ella.

Los objetivos a cumplir en materia de aguas se determinan en la Directiva 2000/60/CE del Parlamenteo Europeo y del Consejo, de 23 de octubre de 2000 , por la que se establece un marco comunitario de actuación en el ámbito de la política de aguas. Mediante esta Directiva marco, la Unión Europea organiza la gestión de las aguas de manera integrada, con el fin de prevenir y reducir su contaminación, formentar su uso sostenible, proteger el medio acuático, mejorar la situación de los ecosistemas acuáticos y paliar los efectos de las inundaciones y de las sequías.

El Estatuto de Autonomía para Andalucía, en su artículo 10.3. $7^{\circ}$, consagra como objetivo en materia de aguas la adecuada gestión del recurso y la solidaridad interterritorial en su uso y distribución. Así mismo, en el artículo 197 se establece que los poderes públicos de Andalucía protegerán el ciclo integral del agua y promoverán su uso sostenible, eficiente y responsable, de acuerdo con el interés general, correspondiendo a la Comunidad Autónoma 
de Andalucía en esta materia el ejercicio de las competencias que se determinan en los artículos 50 y 51 del Estatuto.

Por ello, la política de aguas debe compatibilizar la satisfacción de las necesidades básicas de la población, la buena calidad ambiental de los ecosistemas acuáticos y terrestres asociados, y el desarrollo social y económico de Andalucía.

Esta política, para ser eficaz, requiere de un gran acuerdo social que sea fruto del debate y del consenso entre todos los colectivos, territorios y grupos de interés que gravitan sobre el agua.

En este sentido, la Resolución del Parlamento de Andalucía, de 14 de mayo de 2007, en su punto 1.1 insta al Consejo de Gobierno a que una vez culminado el proceso de transferencia de las cuencas, promueva un acuerdo político y social para el marco normativo de la gestión del ciclo del agua en Andalcuía que, siguiendo los postulados de la normativa europea, contemple la concepción del agua como patrimonio de todos que hay que conservar y permita la mejora de los servicios públicos del ciclo integral del agua que reciben los ciudadanos, así como los derechos de las personas usuarias, incrementando su participación en la toma de decisiones que les afecten, y que apoye a las entidades supramunicipales, para una mejor garantía de calidad y cantidad del recurso.

El Consejo Andaluz del Agua, máximo órgano de consulta y participación social en materia de aguas, en cumplimiento del acuerdo tomado en su reuníón de 17 de septiembre 2008 y tras más de dos medes de debate y reflexión entre los agentes económicos y sociales, con la participación de expertos y científicos, en torno a los distintos aspectos de la gestión del agua, su administración y su financiación, en su reunión celebrada el pasado 5 de diciembre, aprobó las Bases del Acuerdo Andaluz por el Agua.

Este Acuerdo debe suponer un punto de inflexión que refleje las nuevas y diversas concepciones y percepciones que sobre el agua tiene la ciudadanía andaluza y sirva de referente a los poderes públicos para la que sociedad moderna, plurar y dinámica del siglo XXI pueda disfrutar de un medio hídrico y natural saludable, compatibilizado con el uso racional del recurso para todo tipo de actividades.

\section{ACUERDO ANDALUZ POR EL AGUA}

Una sociedad avanzada y tan vinculada tradicionalmente al agua como la andaluza debe superar el concepto de agua como recurso exclusivamente eco- 
nómico y asumir un nuevo enfoque como elemento cultural y ambiental, y factor de prosperidad en su acepción más amplia.

La incorporación de la gestión del Río Guadalquivir a la Junta de Andalucía en cumplimiento de la reforma del Estatuto de Andalucía supone que la inmensa mayoría de los recursos hídricos de nuestra Comunidad Autónoma van a ser gestionados por los andaluces. Esto representa una ocasión inmejorable para dotarnos de los mejores instrumentos de gestión con los que lograr una administración moderna del agua que sepa promover el desarrollo económico sostenible de Andalucía, en el marco que establece la Directiva Marco del Agua de la Unión Europea (en adelante DMA), que fija para el año 2015 el plazo para la recuperación del buen estado de las masas de agua.

Se genera así una oportunidad, que la sociedad andaluza no puede desperdiciar: que nuestra Comunidad Autónoma se deote de una política de aguas propia que incorpore una nueva ética, basada en los conceptos de sostenibilidad, garantía y responsabilidad.

Esta obligación ética cobra más vigencia aún en un contexto de incertidumbre económica como el actual, en el que el agua, un recurso estratégico de carácter transversal a todos los sectores productivos, lejos de ser un factor limitante, puede convertirse en un elemento dinamizador y un motor de inversión para Andalucía. Adicionalmente, los efectos probables del cambio climático sobre el ciclo hidrológico hacen necesario adoptar políticas flexibles y revisar periódicamente los diagnósticos para ajustar objetivos y prioridades.

Los vectores de esa nueva política andaluza del agua son los siguientes:

- La gestión comprometida con las generaciones futuras, lo que implica alcanzar los objetivos europeos sobre el buen estado de las masas de agua y de los ecosistemas asociados.

- La garantía de disponibilidad del agua como elemento básico para las personas y los usos productivos, para la calidad de vida y la creación de empleo y de riqueza.

- El respeto a la unidad de cuenca, la gestión integral del agua, considerando la totalidad de las aguas que conforman el ciclo hidrológico, incluidas las aguas costeras y de transición. 
- La gestión del agua basada en la calidad del servicio que se presta a la ciudadanía, con compromisos explícitos y la participación activa de los agentes sociales y económicos.

- El sistema de tarifación adecuado para recuperar, en la medida de las capacidades económicas, los costes de la gestión del agua, incluidos los costes ambientales, y que al tiempo incentive un uso responsable.

- El impulso a la I+D+i en materia de aguas coordinando esfuerzos de iniciativa pública y privada.

Estos vectores se estructuran en los siguientes apartados:

\section{POR UNA GESTIÓN COMPROMETIDA CON LAS GENERACIONES FUTURAS}

Con el objetivo de:

- Alcanzar un buen estado de las aguas, dentro del plazo que nos hemos dado en la Unión Europea (2015), compatibilizando la restricción ambiental con los usos productivos e invirtiendo la tendencia a la degradación de los ecosistemas.

- Garantizar la disponibilidad del agua, a través de una gestión prudente, teniendo en cuenta los efectos previsibles del cambio climático y situaciones de sequía.

- Proteger el dominio público hidráulico que incluye el agua, el patrimonio hídrico sobre el que discurre y sus zonas de protección.

- Gestionar el riesgo por avenidas, mediante la delimitación y protección de los terrenos inundables y una adecuada gestión de la seguridad de presas, embalses y balsas.

POR UN USO SOSTENIBLE Y CON GARANTÍA DEL AGUA, UN RECURSO FINITO Y VULNERABLE

Con el objetivo de: 
- Garantizar el derecho básico de la población a disponer del agua imprescindible en cantidad y calidad para sus necesidades básicas.

- Garantizar la calidad en la prestación de los servicios del Ciclo Integral del Agua en toda la comunidad autónoma.

- Garantizar el suministro de agua en cantidad y calidad adecuada a la agricultura de regadío, al turismo, a la industria, al sector energético y a otros usos productivos.

- Fomentar el ahorro de agua en todos los usos, en particular en los regadíos, corrigiendo hábitos y prácticas que generen despilfarro.

- Movilizar con la debida cautela los recursos ahí donde existan, teniendo en cuenta que las infraestructuras necesarias deben ser viables desde el punto de vista técnico, económico, social y ambiental.

- Mejorar la gestión de las aguas subterráneas, integrándola con la de las aguas superficiales, residuales y desaladas.

- Poner en marcha con carácter prioritario políticas que mejoren la garantía de los usos ya implantados y regular procedimientos para la implantación de nuevos usos sin perjudicar a los usos existentes.

\section{POR UNA ADMINISTRACIÓN DEL AGUA, MODERNA Y EFICAZ}

Con el objetivo de:

- Reforzar el derecho de la ciudadanía andaluza a la igualdad de trato en sus relaciones con la administración, independientemente de su lugar de residencia.

- Garantizar una Administración del Agua eficiente y moderna, cercana a la ciudadanía y capaz de hacer frente a los retos del agua del siglo XXI en Andalucía.

- Mejorar la transparencia, la información y la participación pública en la gestión del agua. 
- Impulsar la I+D+i y la gestión del conocimiento sobre el agua, como medio para alcanzar los objetivos de optimización de sus usos y recuperación de la calidad de las masas de agua.

POR UNA PARTICIPACIÓN ACTIVA DE LA SOCIEDAD ANDALUZA EN LA POLÍTICA DE AGUAS

Con el objetivo de:

- Facilitar el consenso social y propiciar que la gestión de los recursos hídricos quede al margen de la contienda política, tanto en el ámbito regional como en el provincial y municipal.

- Garantizar el éxito de una planificación hidrológica cercana a la realidad territorial y a la ciudadanía, que concite su apoyo, así como el compromiso de todos los agentes y sectores afectados.

- Encauzar y resolver en función del interés general los conflictos propios de una moderna gestión del agua, inherentes a una sociedad dinámica, democrática y plural en la que coexisten variados y legítimos puntos de vista e intereses.

- Reforzar el compromiso de la sociedad andaluza con la calidad de sus ecosistemas acuáticos, sus ríos, sus riberas, sus paisajes fluviales, su patrimonio hidráulico, así como con la optimización del uso de los recursos desde el punto de vista medioambiental, social y económico.

POR UN NUEVO RÉGIMEN ECONÓMICO FINANCIERO QUE PERMITA ALCANZAR LOS OBJETIVOS DE LA DIRECTIVA MARCO DE AGUA

Con el objetivo de:

- Cumplir las obligaciones derivadas de la DMA, sobre recuperación de costes asociados a la gestión del agua, incluidos los ambientales.

- Hacer efectivos los principios de generalidad y equidad en la contribución a los costes de administración y gestión del agua. 
- Establecer unos bloques homogéneos de tarifarios de nivel regional, que genere igualdad de trato a los usuarios del agua.

- Incentivar a través de las tarifas y cánones del agua la eficiencia y el uso racional y desincentivar el mal uso y el despilfarro.

- Acometer la ejecución de los distintos programas sobre el agua, para alcanzar antes del 2015 los objetivos de calidad ambiental de la DMA.

- Contribuir a través de las inversiones necesarias y la mejora de los servicios, a la reactivación de la economía y a la generación de empleo.

El presente acuerdo tendrá vigencia hasta 2015, año en el que se llevará a cabo una valoración del cumplimiento de sus objetivos, con un seguimiento anual y una evaluación intermedia en 2012, en concertación con los agentes económicos y sociales que permitirá reajustar objetivos e hitos.

A estos efectos se constituirá en el seno del Consejo Andaluz del Agua una comisión de seguimiento integrada por representantes de las organizaciones económicas, sociales y civiles, así como de la administración, que se reunirán al menos una vez al año y ante la que la administración andaluza del agua deberá informar de los avances en los planes, programas y medidas que se deriven de este Acuerdo.

\section{ANEXO}

\section{BASES PARA EL ACUERDO ANDALUZ POR EL AGUA}

1. El agua es un patrimonio común indispensable e insustituible para la vida y un recurso finito muy vulnerable que es necesario conservar y proteger. La gestión del agua debe garantizar la satisfacción de las necesidades básicas de la población y compatibilizar la buena calidad ambiental de los ecosistemas acuáticos y terrestres asociados, con el desarrollo económico y social de Andalucía.

2. La escasez estructural del agua arraigada en la conciencia colectiva de los andaluces y la imposibilidad de seguir incrementando indefinidamente los recursos disponibles nos obligan a abordar la política 
del agua con una nueva ética basada en los conceptos de sostenibilidad, garantía y responsabilidad.

3. En ese contexto de escasez, todos y cada uno de los usuarios del agua debemos ser conscientes de nuestra responsabilidad y de nuestra obligación ética con la conservación, en cantidad y calidad del recurso y con la optimización social, ambiental y económica de su uso.

4. El acuerdo viene a refrendar y a desarrollar la Resolución aprobada por el Parlamento de Andalucía el pasado 14 de mayo, según la cual "la política de agua debe propiciar tanto un consenso político básico de todas las fuerzas parlamentarias que la sitúa al margen de la contienda política, como el máximo consenso social, entendiendo que el agua es un recurso esencial de todos y para todos, así como un factor estratégico para el desarrollo sostenible presente y futuro de Andalucía”.

5. El proceso de planificación hidrológica es una gran oportunidad para alcanzar el objetivo de recuperación del buen estado de las masas de agua fijado para el año 2015 por la DMA. La administración se implicará activamente para abrir ese proceso en todas sus fases, y en particular en estos momentos, en la elaboración del Esquema de Temas Importantes y en el avance del Plan de las distintas cuencas, a la participación de la sociedad.

6. La política de aguas debe tener en cuenta los efectos probables del cambio climático y su impacto sobre el territorio, el medio ambiente y la actividad humana ligada al medio hídrico. Es necesario avanzar en la investigación sobre sus efectos en el ámbito mediterráneo y adecuar la gestión del agua a un contexto de mayor incertidumbre y aumento de la variabilidad y de los eventos hidrológicos extremos, adoptando políticas flexibles y potenciando la revisión periódica de los diagnósticos para ajustar los objetivos y prioridades.

7. El debate del Acuerdo, enmarcado en un ciclo de incertidumbre económica, nos recuerda la importancia de hacer flexibles las estrategias de manera que se posibiliten mecanismos de adaptación a las coyunturas transitorias propias de una sociedad en cambio permanente. En ese contexto, la puesta en marcha de las necesarias inversiones en infraestructuras se configura como una oportunidad. 
8. La perspectiva de la igualdad de género estará presente en la formulación de la política de aguas y en la organización administrativa, al objeto de eliminar los efectos discriminatorios y fomentar la igualdad de género.

9. Se establece como horizonte de este Acuerdo el año 2015. Para corregir desviaciones y valorar el cumplimiento de objetivos, programas y medidas, se llevará a cabo con los agentes económicos y sociales, así como con las organizaciones civiles andaluzas representativas una evaluación intermedia en el año 2012 que informará del grado de cumplimiento.

\section{POR UNA ADMINISTRACIÓN DEL AGUA ANDALUZA MODERNA Y EFICAZ}

10. La asunción por Andalucía de las competencias sobre la práctica totalidad de sus recursos hídricos con la incorporación de la gestión de la parte andaluza de la cuenca del Guadalquivir a la Junta de Andalucía, constituye una oportunidad para dotarnos de una política de aguas propia y de una administración moderna capaz de hacer frente a los retos de la gestión del agua en el Siglo XXI.

11. Esta administración responderá a los principios de eficacia, descentralización funcional, desconcentración funcional y territorial, coordinación, transparencia y proximidad a la ciudadanía que establece la Ley 9/2007, de Administración de la Junta de Andalucía.

12. La nueva administración del agua deberá apostar por la innovación, la plena incorporación de las nuevas tecnologías de la información, la normalización de procedimientos y criterios técnicos, la simplificación de trámites, la reducción de plazos y la transparencia informativa, en el marco del programa de modernización de la administración andaluza anunciado en el discurso de investidura del Presidente de la Junta de Andalucía.

13. El principio de coordinación, entre las distintas administraciones y entre las Consejerías de la Junta de Andalucía, adquiere especial relevancia en la gestión de un recurso con tan diversas y complejas implicaciones medioambientales, sociales, económicas, de organización territorial, sanitarias y de servicio público, además de las inherentes a la prevención del riesgo. Especial mención merece la coor- 
dinación entre administraciones responsables de la gestión de aguas costeras, de transición, continentales superficiales y subterráneas.

14. El principio de proximidad a la ciudadanía se hará efectivo a través de las Direcciones Provinciales. Ese principio es compatible con la realidad del ciclo hidrológico y el respeto a la unidad de gestión de los sistemas hidráulicos y demarcaciones hidrográficas, tal como prescriben el Texto Refundido de la Ley de Aguas (TRLA) y la DMA. Para ello, es necesario explicitar el reparto de funciones y competencias de cada órgano administrativo.

15. En particular, el ámbito para la planificación, la gestión del dominio público hidráulico, la explotación de los recursos y la participación social será la Demarcación Hidrográfica.

16. Se reforzará el derecho a la igualdad de trato de la ciudadanía en sus relaciones con la administración independientemente de su lugar de residencia.

\section{POR UNA PARTICIPACIÓN ACTIVA DE LA SOCIEDAD ANDALUZA EN LA POLÍTICA DE AGUAS}

17. La política de aguas tiene notable influencia sobre la calidad de vida actual y futura de la ciudadanía y condiciona el desarrollo social y económico de Andalucía y su sostenibilidad. Articular la participación social activa y la búsqueda de consensos es una prioridad para todos los firmantes de este acuerdo.

18. La DMA y el TRLA depositan una parte importante de sus esperanzas de éxito en una planificación hidrológica cercana a la realidad territorial y a la ciudadanía, mediante la participación de las partes interesadas, extendiendo dicha participación a la sociedad en general. Los procesos de participación representan una oportunidad para obtener el compromiso de todos los agentes.

19. El consenso social debe permitir a Andalucía dotarse de un marco legal propio, que defina el papel de la administración y la participación activa de la sociedad en la definición y ejecución de la política de aguas, bajo los principios de colaboración, coordinación, respeto institucional y mutua lealtad de las administraciones. 
20. Esa participación activa incluye además de los usuarios y gestores, a los agentes económicos y sociales, consumidores y vecinos, organizaciones de defensa de intereses ambientales, científicos y técnicos del área del conocimiento hidrológico y usos del agua, a través de su incorporación al Observatorio del Agua y órganos colegiados para la toma de decisiones generales y estratégicas sobre la política de aguas y la planificación hidrológica.

21. La participación de los usuarios y gestores en los ámbitos de explotación es fundamental para garantizar el acuerdo en la gestión del dominio público hidráulico y en la explotación de los recursos.

22. Una moderna gestión del agua debe ser capaz de encauzar y resolver conflictos entre colectivos y territorios, integrados por personas de una sociedad democrática y plural en la que coexisten variados puntos de vistas y legítimos intereses. Para ello, se articularán procedimientos que exploren las áreas de entendimiento y estrategias de acuerdo y consenso.

23. El impulso de los programas específicos de educación, voluntariado y divulgación ambiental contribuirá a fortalecer el compromiso de la sociedad andaluza con la calidad de sus ecosistemas acuáticos y terrestres asociados y la optimización del uso de los recursos desde el punto de vista medioambiental, económico y social.

24. La transparencia, la información y la participación pública son ejes fundamentales para la mejora de gestión de los servicios de agua. El Observatorio Andaluz del Agua, pionero en España, está llamado a ser el órgano de participación e información sobre el agua. La Administración se dotará de mecanismos para exigir información comparable y fiable, y para elaborar reglamentos y directrices que faciliten la intervención de la administración con el fin de mejorar y armonizar la prestación de servicios. En aras de una administración eficiente, no se obligará a los agentes implicados a duplicar las informaciones o gestiones a las que ya vienen obligados.

25. Una ley de Aguas andaluza consensuada entre todas las fuerzas políticas y sociales, unos mecanismos eficaces de participación social y una administración del agua moderna, eficiente y transparente, permitirán a Andalucía alcanzar los objetivos medioambientales de ges- 
tión sostenible y protección de los recursos hídricos establecidos en la DMA, que asume como propios, y promover una política que garantice que el agua no sea un factor limitante de nuestro desarrollo.

\section{POR UN USO SOSTENIBLE Y CON GARANTÍA DEL AGUA, UN RECURSO FINITO Y VULNERABLE}

\section{Servicios urbanos del agua}

26. El consumo doméstico de agua en cantidad y calidad acorde a los criterios sanitarios vigentes, es un derecho básico de la población. La administración pondrá en marcha planes y programas para alcanzar el objetivo de que los ciudadanos y ciudadanas, cualquiera que sean su capacidad económica y su localidad de residencia, dispongan de un suministro mínimo de agua. Al mismo tiempo, establecerá políticas de estimulación del ahorro y disuasorias del consumo excesivo.

27. El Observatorio Andaluz del Agua fijará las normas, criterios técnicos y la metodología para la cuantificación de las pérdidas en redes urbanas.

28. En consonancia con la percepción social y la constatación técnica de la escasez del recurso, se pondrá especial énfasis en las políticas de ahorro y empleo eficiente del agua. En consecuencia, será objetivo básico de las administraciones públicas la reducción de las pérdidas en todas las fases del ciclo y para todos los usos, y se establecerán umbrales y horizontes temporales para su reducción.

29. La administración garantizará la calidad en la prestación de los servicios del Ciclo Integral del Agua para todo la Comunidad Autónoma mediante la promulgación de estándares de calidad elaborados por el Observatorio, que definirán requerimientos mínimos de servicio incluida la representación de la sociedad en los órganos de gestión. Su definición se realizará junto a las entidades de gestión y promoverán la unificación y simplificación de las estructuras tarifarias, actualmente muy variadas, de compleja comprensión e imposible tipificación.

30. El sistema de tarifación del consumo de agua para uso doméstico, al igual que para el resto de usos, será volumétrico de forma que se in- 
centive el ahorro, bonificando el uso responsable del recurso, y actuando en consecuencia sobre el derroche.

31. Se establecerá una normativa técnica del servicio del ciclo integral del agua, que tendrá carácter subsidiario y será de obligado cumplimiento en todos aquellos municipios que carezcan de su propia norma. Actualizará el reglamento de suministro domiciliario y regulará las cuestiones técnicas de vertido a la red municipal de alcantarillado de manera que no se produzcan efectos negativos en las infraestructuras e instalaciones públicas. Se observará especial cuidado en no establecer requerimientos distintos e injustificados que generen un agravio por su ubicación geográfica entre actividades similares.

32. La prestación del servicio de agua para consumo domiciliario con la calidad y la eficiencia que demanda la ciudadanía andaluza requiere de un impulso decidido a la constitución, consolidación y potenciación de entidades supramunicipales. Se aprovechará la experiencia de los gestores de los servicios que han mostrado ya su eficacia en cada ámbito geográfico.

33. El éxito en la definición del ámbito supramunicipal de la prestación del servicio depende de una correcta interlocución. El diálogo directo de la Junta de Andalucía con las aglomeraciones urbanas se ha revelado especialmente fructífero. En el caso de los municipios pequeños y medianos no integrados en una aglomeración, es imprescindible contar con la implicación activa de las Diputaciones Provinciales como interlocutores, para abordar la definición de los ámbitos de gestión, las cuestiones pendientes en materia de infraestructuras y la explotación de las instalaciones y gestión del sistema.

34. Las entidades supramunicipales deben definirse con criterios de racionalidad y eficacia, teniendo en cuenta no sólo la unidad de abastecimiento, sino también su capacidad de autogestión y autosuficiencia. Es en el ámbito provincial donde deben planificarse las infraestructuras y los sistemas de gestión del ciclo integral del agua de uso urbano, con la implicación directa de las diputaciones y la participación de los consorcios provinciales y sistemas de gestión consolidados.

35. Para alcanzar los objetivos de la DMA, es indispensable llevar a cabo un plan de medidas que permita disponer de unos ríos, lagos, acuífe- 
ros y aguas costeras ecológicamente saludables, con valores recreativos y paisajísticos reconocidos y, en general, de disfrute de la naturaleza.

36. Para alcanzar los objetivos de calidad de nuestros ríos es imprescindible completar la red de depuradoras en aquellos municipios que todavía carecen de ella, especialmente en el medio rural, y ampliar las infraestructuras existentes en las grandes ciudades y en el litoral cuando se requiera. Los gestores habrán de dotarse de mecanismos que garanticen la operación y el mantenimiento de las infraestructuras a costes asumibles por la ciudadanía.

37. Para garantizar la consecución de los objetivos, se definirá claramente el ámbito competencial de las distintas administraciones en la gestión del ciclo integral del agua, sobre las que recaerá la correspondiente responsabilidad.

38. La administración del agua reforzará los controles sobre el correcto funcionamiento de las infraestructuras construidas y activará todos los mecanismos legales para que éste sea el adecuado, aplicando las medidas normativas que correspondan en cada caso.

39. Se establecerán, a través del Observatorio de Agua, los mecanismos pertinentes de información, seguimiento y evaluación de la ejecución del plan de medidas.

40. La administración, junto con los agentes económicos y sociales, impulsará la $\mathrm{I}+\mathrm{D}+\mathrm{i}$ en tecnologías del ciclo del agua, así como programas de formación para gestores de los servicios públicos de abastecimiento y saneamiento de aguas.

41. Se articulará, en colaboración con las organizaciones interesadas, los agentes económicos y sociales y los gestores, un proceso informativo y divulgativo al objeto de que la ciudadanía se conciencie de la importancia del consumo responsable y de la aplicación de la DMA en beneficio de la garantía de suministro, su calidad y la conservación y protección del medio ambiente.

\section{El agua como recurso productivo}

42. El agua como factor productivo ha desempeñado y debe seguir desempeñando un papel fundamental en la articulación territorial y en 
el desarrollo económico y social de Andalucía. La agricultura de regadío, proveedora de alimentos y materias primas, así como el turismo, la industria o el sector energético, entre otros, generan empleo, riqueza y equilibrio territorial y demandan servicios de agua con garantía de suministro y calidad suficiente para desarrollar su actividad.

43. La gestión sostenible del agua no es posible sin planificación. Los planes hidrológicos que se están elaborando en el marco de la DMA y que deberán culminarse en el año 2009, constituyen un hito fundamental en la concreción de la política del agua y su plasmación en el territorio.

44. La planificación hidrológica de las Demarcaciones Hidrográficas del Guadalquivir, Guadiana y Segura se llevará a cabo por la Administración General del Estdo en estrecha colaboración con la Junta de Andalucía, mientras que en el resto de las Demarcaciones andaluzas la competencia corresponde íntegramente a la Junta de Andalucía.

45. La gestión sostenible del agua no es posible sin un conocimiento detallado de la realidad. La administración destinará los medios necesarios para actualizar en corto plazo los registros de titulares de los derechos de agua y su cuantía, a fin de tener un reflejo administrativo lo más exacto posible de cómo se está usando el agua. Esta información sobre derechos y usos se pondrá a disposición de la ciudadanía a través de la página Web del Observatorio del Agua, observando las cautelas necesarias para cumplir las previsiones de la Ley de protección de datos de carácter personal.

46. El Acuerdo Andaluz por el Agua asume como propias las soluciones para el control de las demandas aprobadas en Junta de Gobierno relativas al Acuerdo por el Agua en la Cuenca del Guadalquivir.

47. Ante demandas o actividades que incrementen la tensión entre disponibilidad de recursos y necesidades de suministro, y hasta tanto la planificación lo permita, primará el principio de cautela en la autorización de nuevos usos. Cualquier nueva actividad sólo se autorizará cuando disponga de recursos de agua. En cualquier caso, se tendrá en cuenta el principio de no perjudicar a la garantía de los usos consolidados.

48. En los sistemas con sobredemanda de agua, la disponidilidad futura de recursos se destinará a la recuperación del buen estado de las ma- 
sas de agua y a garantizar los usos consolidados, prioritariamente el abastecimiento urbano. Procederá fundamentalmente de la modernización de los regadíos, la mejora de la gestión, la reutilización de aguas depuradas y la desalación.

49. Se finalizarán las inversiones en curso para captación de nuevos recursos. Donde existan recursos movilizables, se llevarán a cabo las inversiones necesarias, en función de las disponibilidades presupuestrias, para la construcción de infraestructuras convencionales (regulación y transporte) o de nuevas tecnologías (regeneración de agua depurada y desalación), siempre que sea compatible con los objetivos ambientales.

50. Se establece el horizonte 2015 para la culminación del proceso de modernización de regadíos, que actualmente avanza con buen ritmo en Andalucía gracias a la confluencia de esfuerzos públicos y privados. En el plazo de un año tras la firma del Acuerdo, se procederá a la adecuación de las concesiones mediante el ajuste de dotaciones de todas las zonas modernizadas, conforme a las determinaciones de la planificación hidrológica. Así, se hará efectivo el ahorro de agua que justifica la inversión pública y se permitirá que la reducción de consumo se destine al bien común. A partir del 2015, ese ajuste se aplicará a todas las zonas de riego que hayan dispuesto de la oportunidad de beneficiarse del apoyo público para la modernización de sus infraestructuras, independientemente de que la hayan llevado a cabo o no.

51. En todos aquellos usos en los que se pueda producir ahorro en beneficio de la colectividad, se llevarán a cabo iniciativas conjuntas con el sector privado que contribuyan a alcanzar los objetivos del acuerdo.

52. Se establece el horizonte 2015 para la generalización de la facturación por consumo a todos los titulares de derechos de agua, penalizando tarifariamente los consumos abusivos y la inadecuada gestión del recurso.

53. La mejora de la gestión del agua es una de las medidas con más potencial para un ahorro efectivo de agua en las explotaciones agrícolas. Se reforzarán en colaboración con las administraciones competentes, los programas de $\mathrm{I}+\mathrm{D}+\mathrm{i}$ destinados al cálculo agronómico de las necesidades de agua de los cultivos y a la implantación de riegos 
deficitarios, etc., formación y apoyo técnico a los regantes y a las comunidades de regantes para mejorar la eficiencia del riego, reducir la vulnerabilidad de las explotaciones ante las fluctuaciones en la disponibilidad de agua y permitir una reducción sustancial de las dotaciones actuales sin merma de rentabilidad económica.

54. Para impulsar nuevas técnicas que permitan el uso eficiente y el ahorro del recurso en los sectores productivos, se pondrán en marcha programas y medidas con los agentes económicos y sociales.

55. La transferencia de recursos entre territorios se articulará a través de programas específicos de gestión, que incorporarán tanto las reglas de explotación como las medidas compensatorias que en su caso procedan.

56. Por su carácter estratégico, se fomentará el empleo del agua residual urbana regenerada. Sin embargo, ese agua no puede, en general, considerarse como un nuevo recurso, salvo en el litoral y siempre que no esté siendo ya utilizada. En el interior de Andalucía, la disponibilidad de esos caudales sin una planificación previa supondría una merma de garantía a los usuarios aguas abajo.

57. En los casos que por interés general se modifique un aprovechamiento consolidado a favor de otro, el usuario beneficiado tendrá que compensar al perjudicado.

58. La administración regulará los procedimientos adecuados para que se cumpla el principio de no perjudicar a la disponibilidad de recursos. En particular, se analizará y potenciará la figura del Banco Público de Agua como herramienta de disponibilidad de agua para la atención de demandas prioritarias o de interés general, en especial la medioambiental y la de recursos alternativos en sequía. El Banco Público de Agua deberá operar bajo criterios de control público, transparencia e información y aplicación del principio de cautela, en relación con los posibles efectos socioeconómicos, territoriales y medioambientales de cambios de usos.

\section{Aguas subterráneas}

59. La unidad del ciclo hidrológico exige una gestión conjunta de las aguas subterráneas y superficiales incluidas las residuales regeneradas, así como las procedentes de la desalación. 
60. Las aguas subterráneas desempeñan un papel muy importante y estratégico especialmente en ciclos de sequía, tanto para el abastecimiento de agua como para las actividades productivas entre las que se encuentran los riegos intensivos de litoral. Son las que sostienen los caudales de estiaje de los ríos y garantizan la regularidad en los abastecimientos.

61. La administración impulsará la investigación hidrogeológica con el fin de alcanzar un adecuado conocimiento de las masas de agua subterránea y llevará a cabo un seguimiento de su estado cuantitativo y cualitativo y de los ecosistemas asociados. Esa información se pondrá a disposición de la ciudadanía, tan pronto como se conozca y en el futuro, a través del Observatorio del Agua.

62. Se fomentará el autocontrol mediante la constitución de Comunidades de Usuarios, dotadas de capacidad de intervención y gestión. En estas Comunidades se podrán incluir tanto las aguas subterráneas como superficiales o de otra procedencia. Además, se integrarán tanto los usuarios con concesión como los titulares de aguas privadas, bajo el principio de eficacia de gestión mediante la implicación plena de todos los usuarios, a través de los órganos de participación de la administración del agua, y localmente, de sus propias estructuras de gestión de las masas de aguas.

63. Se estudiarán fórmulas para que todas las infraestructuras de captación, transporte y distribución general en el ámbito geográfico de una comunidad de regantes sean gestionadas por ésta con criterios y reglas de explotación a definir por la propia organización.

64. Cuando sea necesaria la organización general de la explotación de un acuífero mediante una Comunidad de Usuarios y sobre el mismo territorio esté ya constituida una o varias Comunidades de Regantes, se constituirá una Junta Central de Usuarios que realice conjuntamente la gestión de recursos de cualquier fuente o procedencia.

65. En caso de no constituirse voluntariamente y cuando así lo requiera la gestión del recurso y la protección del medio ambiente, la administración podrá instar la constitución de la Comunidad de Usuarios. En estos ámbitos, se pondrán en marcha obligatoriamente programas de recuperación consensuados con los agentes afectados. Para cubrir los 
costes de constitución, se cuantificarán los gastos de primer establecimiento dotándose de mecanismos financieros adecuados.

66. Los programas de medidas a contemplar en los Planes Hidrológicos serán los instrumentos indicados para la recuperación de las masas de aguas subterráneas en riesgo. Ordenarán el régimen de extracciones hasta alcanzar el buen estado de la masa de agua, así como la recuperación de los manantiales y ecosistemas terrestres asociados.

\section{POR UNA GESTIÓN COMPROMETIDA CON LAS GENERACIONES FUTURAS}

67. El compromiso con las generaciones futuras constituye un objetivo medular y transversal de las políticas impulsadas por la Junta de Andalucía. La política del agua emana de ese compromiso, que impregna también los objetivos de la DMA.

68. La protección del dominio público hidráulico abarcará tanto al recurso como al patrimonio hídrico, garantizando en la medida de las posibilidades la continuidad ecológica de las zonas fluviales, la protección del régimen de las corrientes en avenidas y la recuperación de los ecosistemas y de los paisajes fluviales. En particular, se establecerán medidas específicas de recuperación de riberas, y de conservación preventiva de los cauces públicos.

69. Se reforzarán, en coordinación con las Consejerías implicadas, las medidas que favorezcan la lucha contra la erosión reduciendo los efectos negativos de arrastres, entre ellos el aterramiento de embalses. Es necesario la realización de labores de restauración hidrológico-forestal y la gestión sostenible de los ecosistemas forestales existentes en las cuencas, especialmente en sus cabeceras.

70. Cuando las construcciones o las instalaciones fijas, nuevas o existentes, representen un riesgo de daños por avenidas a las personas o bienes, se aplicará el concepto de "línea probable de deslinde" similar al establecido en la Ley 22/1988 de Costas.

71. El régimen de caudales ecológicos, quedará determinado en los planes hidrológicos de manera que se avale la calidad de los ecosistemas, preservando la restricción ambiental de acuerdo con lo que establece el TRLA. 
72. La determinación del régimen de caudales ecológicos de las masas de agua se basará en modelos científico-técnicos. En el marco del proceso de acuerdo con los agentes afectados se realizarán la simulación de afecciones y análisis de sensibilidad que permita el ajuste entre demandas a satisfacer y requerimientos ambientales.

73. El objetivo de alcanzar la buena calidad de los ecosistemas acuáticos y terrestres asociados en los plazos establecidos por la DMA, exige un especial esfuerzo para paliar la contaminación difusa, actuando desde la prevención sobre las fuentes de suministro, estableciendo medidas de control, fomentando prácticas sostenibles, y habilitando medios para la formación y la investigación de interrelaciones agua-suelo-planta. La identificación de fuentes de contaminación difusa ajenas a la actividad agraria y las medidas para corregirla serán objeto igualmente de atención prioritaria.

74. En el plazo de cuatro años, la administración del agua culminará la delimitación de las zonas inundables ya iniciada y establecerá, en coordinación con las administraciones competentes, las medidas a tomar para evitar la ocupación de cauces.

75. Se adoptarán instrumentos normativos para reforzar la protección de los terrenos inundables con el fin de evitar su ocupación, incorporando los preceptos de gestión del riesgo de la Directiva Europea sobre Inundaciones, y se eliminarán los obstáculos al drenaje de avenidas presentes en las vías de intenso desagüe. Complementariamente, se actualizará el Decreto 189/2002 de "Prevención de avenidas e inundaciones en cauces urbanos andaluces".

76. Los instrumentos de ordenación territorial y urbanística deberán prever los efectos y establecer medidas correctoras que minimicen las afecciones que sobre los caudales de avenida, supone la alteración de las condiciones hidrológicas de las cuencas de aportación, como puede ser la disminución de la capacidad de infiltración de agua.

77. Además de la seguridad frente a fenómenos extremos, como las inundaciones, la seguridad de las presas, embalses y balsas constituye un aspecto ineludible a abordar por la administración. Es necesario adaptar al ámbito autonómico la normativa estatal sobre seguridad de presas y embalses, además de regular las normas de seguridad de balsas ubicadas al margen del dominio público hidráulico. 
78. Se aprobarán los Planes Especiales de actuación en situaciones de alerta y eventual sequía de las cuencas internas andaluzas. La estrategia ante sequías se basará en las medidas previstas en dichos planes. Se extremarán los esfuerzos de información y difusión para trasladar a los usuarios las medidas que se deben tomar en cada fase de la sequía.

79. Se extenderá a los municipios y sistemas de abastecimiento andaluces de más de 10.000 habitantes la obligación de redactar Planes de Emergencia ante situaciones de sequía, ofreciendo asesoramiento técnico a aquellos municipios, diputaciones o mancomunidades que lo soliciten.

80. Se fomentará la construcción de pequeñas infraestructuras de regulación local, cuando no afecten a derechos de otros usuarios y su ejecución sea compatible con los objetivos ambientales, lo que permitirá afrontar con mayor garantía de éxito los ciclos de escasez de agua y adaptar la disponibilidad del recurso a las necesidades del abastecimiento humano, de los cultivos y otros usos.

81. La interconexión de sistemas permite la diversificación de las fuentes de suministro, haciéndolos permeables, e incrementa notablemente la seguridad de atención de demandas prioritarias en ciclos de escasez en la disponibilidad de agua.

\section{HACIA UN NUEVO RÉGIMEN ECONÓMICO FINANCIERO, QUE PERMITA ALCANZAR LOS OBJETIVOS DE LA DIRECTIVA MARCO DEL AGUA}

82. La obligación de alcanzar el buen estado de las masas de agua, consolidar el uso productivo con garantía del recurso y cumplir estándares de calidad en el servicio público del agua obligan a la revisión del actual régimen económico financiero del agua, que debe responder a los principios de generalidad, equidad, calidad en el servicio, incentivación de la eficiencia, responsabilidad medioambiental y transparencia.

83. Es necesario tender al principio de recuperación de costes establecido en la DMA, en el que se incluyen los costes de explotación, ambientales, de amortización de infraestructuras, laminación de avenidas y de oportunidad. Es irrenunciable el principio de "quien contamina paga" cuya aplicación contribuirá a hacer respetar y cuidar un recurso que es de todos. 
84. De acuerdo a las previsiones de la DMA será necesario definir un régimen de excepciones en las exigencias para alcanzar los objetivos medioambientales cuando resulte desproporcionado repercutir íntegramente los costes al beneficiario.

85. Todos los usuarios deben contribuir a la financiación de los gastos de gestión del agua de forma equitativa y proporcional a los servicios recibidos.

86. Las tarifas y cánones se establecerán proporcionales al consumo e incentivarán la eficiencia y el uso racional. Hasta tanto se generalice la tarifación por volumen en 2015, se implantará progresivamente donde se disponga de contador. El consumo excesivo y las pérdidas serán objeto de un tratamiento económico específico.

87. Se estudiarán formas de financiación y reparto de aquellas cargas relacionadas con las infraestructuras a fin de evitar que supongan un freno para el desarrollo de Andalucía.

88. La recuperación de la calidad de nuestros ecosistemas, imperativo de la DMA y demanda social creciente, nos obliga a llevar a cabo un esfuerzo especial como Comunidad, con el fin de financiar las infraestructuras de abastecimiento, saneamiento y depuración pendientes, garantizando su correcto funcionamiento.

89. Se creará el "canon de infraestructura urbana del agua" de carácter finalista, mediante el que los beneficiarios del ámbito urbano contribuirán a la recuperación de inversiones en materia de abastecimiento, saneamiento y depuración. Junto al canon, la creación de los medios operativos pertinentes para llevar adelante las inversiones en un horizonte temporal de corto plazo, permitirá alcanzar los objetivos de calidad de la DMA, completando los importantes esfuerzos inversores ya realizados.

90. Ese canon en el caso del uso doméstico contará con factores de corrección en función de la unidad familiar. Se implantará a lo largo de un periodo de cinco años, impidiendo la doble imposición a los usuarios que ya contribuyen a las inversiones en abastecimiento, saneamiento y depuración mediante el pago del canon de mejora. Al objeto de garantizar los servicios básicos de suministro de agua, la Ley establecerá el régimen de exenciones por causas extraordinarias. 
91. El Observatorio del Agua propondrá la adopción de medidas tendentes a la homogeneización del sistema tarifario del ciclo urbano en el conjunto de municipios andaluces, al objeto de propiciar sistemas de bloques progresivos acordes con los previstos en el canon de infraestructura urbana del agua, determinando los tramos o bloques de consumo básico, ordinario y excesivo.

92. Se procurará arbitrar acuerdos con entidades financieras, y especialmente con las cajas de ahorro andaluzas, al objeto de facilitar el acceso de los usuarios a créditos que permitan realizar inversiones que mejoren la eficiencia en las redes domésticas, con especial consideración a la sustitución de contadores comunitarios por individuales.

93. La reforma del régimen económico-financiero del agua se acompañará de una profunda modernización de la gestión, que permitirá la confección de los borradores administrativos de autoliquidación, presentación telemática de la declaración y pago de los diferentes cánones y el empleo de todos los servicios y herramientas de la Oficina Virtual Tributaria.

\section{Reactivación de la economía y el empleo}

94. En la actual coyuntura de crisis económico-financiera mundial, el importante volumen de inversiones en modernización de regadíos, saneamiento, depuración, conducciones, abastecimiento, conservación de cauces y demás infraestructuras que deberán ejecutarse para alcanzar los objetivos previstos en el presente Acuerdo, van a tener un efecto positivo sobre la actividad productiva y la generación de empleo.

95. La puesta en marcha de nuevos servicios del agua y mejora de los existentes, generará oportunidades para la creación y consolidación de empresas y puestos de trabajo, en particular en el medio rural.

96. Con el fin de acelerar la ejecución de las infraestructuras necesarias y su pronta puesta en servicio, los recursos públicos se complementarán con mecanismos de financiación-privada.

97. Las medidas para alcanzar los objetivos del Acuerdo Andaluz por el Agua, se incorporan al conjunto de medidas de impulso a la economía puestas en marcha por la Junta de Andalucía. 